\title{
Dispositional playfulness in young children: A cross-sectional and longitudinal examination of the psychometric properties of a new child self-reported playfulness scale and associations with social behaviour
}

\author{
Elian Fink $^{1,2}$ (1) | Silvana Mareva ${ }^{1}$ (i) | Jenny L. Gibson ${ }^{1}$ (i) \\ ${ }^{1}$ Centre for Research on Play in Education, Development and Learning, Faculty of Education, University of Cambridge, \\ Cambridge, UK \\ ${ }^{2}$ Centre for Family Research, University of Cambridge, Cambridge, UK
}

\section{Correspondence}

Elian Fink, Faculty of Education, University of Cambridge, 184 Hills Road, Cambridge CB2 8PQ.

Email: ef364@cam.ac.uk

\begin{abstract}
Most research on children's play takes a context-dependent, adult-focused observational approach to the measurement of play. The current two studies present the development and psychometric properties of the Child Self-Report Playfulness (CSRP) scale, which was presented via "puppet-show" to two samples of children. Study 1, across 98 children between 5 and 7 years of age, showed that the items of the CSRP had good internal consistency, were stable across the 6-week test-retest period and, for the most part, showed no differential item functioning across age, gender, and language ability. Study 2 involved a longitudinal sample of children followed from Reception (age 5, N = 244) to Year 1 (age 6). Findings revealed favourable psychometric properties using longitudinal confirmatory factor analysis and measurement invariance. Associations between child playfulness and teacher- and peer-ratings of social behaviour were examined, and showed specific associations between playfulness and teacher-rated play interaction, rather than social maturity,
\end{abstract}


problem behaviour or social preference. Overall, the CSRP appears to be a promising approach to the measurement of dispositional playfulness in young children.

\section{Highlights}

- We developed a Child Self-Reported Playfulness scale (CSRP) to assess children's perceptions of their own playfulness.

- Across two separate samples, the CSRP had favourable psychometric properties, was stable across the ages of 5 and 6 and showed specific associations with teacher-rated play.

- The findings of the current studies have important implications for our understanding and measurement of children's play across development.

\section{KEYWORDS}

play, playfulness, self-concept, social behaviour

\section{1 | INTRODUCTION}

While there is a growing interest in the developmental outcomes associated with children's play (e.g., Lillard et al., 2013), the vast majority of research on children's play takes a context-dependent adult-focused view of play, such as coding specific behaviours enacted by children in a playful context (e.g., Dunn, Cutting, \& Fisher, 2002; Gibson, Fink, Torres, Browne, \& Mareva, 2019; Leach, Howe, \& DeHart, 2019) or asking teachers to report on children's play interactions with peers (e.g., Fantuzzo \& Hampton, 2000). In this way, there is a view of play that is very much centred on the setting of play rather than playfulness as a characteristic of the child. Given the difficulties facing the play literature in both defining and empirically assessing play in childhood, attempting to understand play from its observable behaviours has been challenged and the importance of bringing in the child's own voice has been stressed (e.g., Barnett, 1990; Howard, 2002). The current studies report on the psychometric properties of a scale developed to assess young children's self-perceptions of themselves as playful; specifically we test, across both a cross-sectional and longitudinal sample, the reliability and stability of children's self-reported playfulness and associations between self-reported playfulness and teacher-reported play, social maturity and problem behaviours, and peer-reported social preference.

\section{2 | WHY MEASURE PLAYFULNESS IN CHILDREN?}

While many studies focus on play as an activity or behaviour, Barnett (1990) suggested that "empirical attention should be focused on the playful child, rather than the child at play" (p.320). Barnett defines playfulness as "the predisposition to frame (or reframe) a situation in such a way as to provide oneself (and possibly others) with amusement, humour, and/or entertainment" (Barnett, 2007, p. 955) and argues that such dispositional playfulness is linked to children's creativity, socioemotional adjustment and cognitive abilities (Barnett, 1991a, b). Playful engagement has been linked to social adjustment in humans and other species-possibly through mechanisms involved in stress regulation and environmental adaptation (Pellis \& Pellis, 2013). This is pertinent to discussions of the role of play in 
children's development and wellbeing as these topics are gaining increasing attention in policy arenas (e.g., UNICEF, 2018), but little research has examined empirically the influence of different conceptualisations of play/ playfulness and the chosen measurement strategies upon the conclusions that are drawn.

The relevance of addressing these issues is supported by recent work employing sophisticated analytic approaches, such as Actor-Partner Interdependence Modelling which takes into account the interdependent nature of children's play, that have demonstrated the overwhelming role of context, specifically play partner, in determining children's observed behaviours in play rather than children's own cognitive skills, such as language or perspective taking abilities (e.g., Etel \& Slaughter, 2019; Gibson et al., 2019; see also Youngblade \& Dunn, 1995). Furthermore, when attention is focused on evaluating the literature on the links between children's play and their cognitive and social outcomes findings have been inconclusive, at least for pretend play (Lillard et al., 2013). This suggests that a focus on children's tendency toward playfulness may be a fruitful avenue of research and complement research focused on observed play behaviours.

Further, in research with adults, play as a feature of an individual's personality is considered an important approach to understanding play in adulthood. Research conducted on playfulness as a personality trait in adults has shown encouraging psychometric results (e.g., Glynn \& Webster, 1992; Proyer \& Ruch, 2011; Shen, Chick, \& Zinn, 2014) and are typically measured using self-report questionnaires assessing constructs such as spontaneity, expressiveness, fun, creativity and silliness (Adult Playfulness Scale; Glynn \& Webster, 1992), or fun-seeking, motivation, uninhibitedness, and spontaneity (Adult Playfulness Trait Scale; Shen et al., 2014). Measures of playfulness in adults has revealed associations between greater self-perceptions of playfulness and positive psychological functioning and wellbeing (Proyer, 2012; Proyer \& Ruch, 2011; Yue, Leung, \& Hiranandani, 2016). These observed associations lead to questions about the ontogeny of these aspects of development throughout childhood and adolescence.

\section{3 | THE MEASUREMENT OF PLAYFULNESS IN YOUNG CHILDREN}

Playfulness has been assessed in young children via both teacher report (Barnett, 1990, 1991b; Trevlas, Grammatikopoulos, Tsigilis, \& Zachopoulou, 2003) and observations of child behaviour (e.g., Bundy, Nelson, Metzger, \& Bingaman, 2001; Singer, Singer, \& Sherrod, 1980). Teacher-report measures of playfulness, as assessed by the Children's Playfulness Scale (CPS), developed by Lieberman (1965) and refined by Barnett (1990, 1991b), includes the child characteristics of humour and joy (e.g., joking, singing, and laughter), flexibility (e.g., using unconventional objects in play, imagination), physical activity, and social competence (e.g., initiating and maintaining play with peers). The items of the teacher-rated Children's Playfulness Scale (Barnett, 1990) have been shown to be reliable, that is, have high internal consistency, strong inter-rater reliability, and load onto a single playfulness factor for children between 3 and 6 years of age (Barnett, 1990, 1991b; Trevlas et al., 2003).

Observational measures of children's playfulness highlight similar characteristics as teacher-reported measures, with behavioural coding focusing on positive affect, internal motivation, social and imaginative play, suspension of reality, and verbal skills as features of the playful child (Bundy et al., 2001; Singer et al., 1980). Examining the longitudinal stability of an observational measure of playfulness with 87 preschool-aged children showed that it was moderately stable over one year $(r=.29$, Singer et al., 1980). Furthermore teacher-rated and observational measures of playfulness have been shown to be positively associated in both typical (Barnett, 1991b; Bundy et al., 2001) and atypical groups of children, for example with children who have physical disabilities or Autism Spectrum Disorders (Harkness \& Bundy, 2001; Muys, Rodger, \& Bundy, 2006).

\section{4 | CHILDREN'S SELF-CONCEPT}

Despite a tradition within the play research of measuring child playfulness using teacher report, it is arguably children themselves who are best placed to report on their own playfulness. Indeed, it has been shown that from preschool- 
age, children are able to articulate a clear understanding of the distinction between play and not-play (Howard \& McInnes, 2013; Wing, 1995) and report on their own play behaviours (Rothlein \& Brett, 1987). While, older children are able to report reliably using questionnaire methods directly on their own play (e.g., Barnett, 2013) and young adults can report on their own playfulness (Barnett, 2007). Nonetheless young children have yet to be asked to report on the degree to which they conceptualize themselves as playful, that is to report on their own playful self-concept.

Children's self-concept is considered "the cornerstone of both social and emotional development" (Kagen, Moore, \& Bredekamp, 1995 p. 18) and as a result there has been a specific focus on measurement of early emerging self-concept, and on how children's self-concept may reflect social competencies (e.g., de Rosnay \& Fink, 2012; Donnellan, Trzesniewski, Robins, Moffitt, \& Caspi, 2005; Measelle, Ablow, Cowan, \& Cowan, 1998). In response to the challenge of ensuring reliable measures that capture children's own perceptions of their behavioural and psychological selves, a "puppet-show" method was developed (see Eder, 1990; Measelle et al., 1998), which allows the presentation of self-concept items in an age-appropriate manner. Presenting self-concept items via puppets increases the likelihood the young child will remain engaged with the task and limits the language burden on the child, as they may simply point to the puppet that is "most like them". When using age-appropriate methods, studies have shown that children as young as 4 and 5 years of age are able to reliably report on their own self-concept at a domain-level (e.g., physical, peers, verbal, math; Marsh, Ellis, \& Craven, 2002) and that children's own reported self-concept is meaningfully associated with both mother-reported personality (Brown, Mangelsdorf, Agathen, \& Ho, 2008) and teacher-reported social competencies and problem behaviours (de Rosnay \& Fink, 2012).

While self-perceptions of playfulness have not yet been assessed in young children, several self-report scales do assess children's perspectives on two broadly related constructs: social competence and peer acceptance (Harter, 1985; Measelle et al., 1998). The most frequently used questionnaires for assessing children's social selfconcept are the Self-Perception Profile for Children (Harter, 1985), assessing social acceptance (e.g., "I find it easy to make friends") one of five domains of self-concept, and the Berkeley Puppet Interview (BPI Measelle et al., 1998) assessing both the domain of social competence (e.g., "I ask kids to play") and peer acceptance (e.g., "Kids ask me to play"). There is some evidence for the stability of child-reported social competence. For example, using the Harter social acceptance subscale, Granleese and Joseph (1994) found a correlation of 0.29 between 8 and 11 years of age, while Putnick, Hahn, Hendricks, and Bornstein (2019) found a correlation of 0.22 between age 4 and 10 years. Impressively, using the BPI, Measelle et al. (1998) found longitudinal correlations of 0.51 and 0.55 for the social competence and peer acceptance scales, respectively, across Kindergarten to Year 1. Furthermore, research has found that children's social self-concept, as measured by the Harter scale and the BPI, are meaningfully associated with peer-, teacher-, and mother-ratings of children's social competencies (e.g., Boivin, Vitaro, \& Gagnon, 1992; Measelle et al., 1998) and negatively associated with parent-reported externalizing and internalizing problems (Muris, Meesters, \& Fijen, 2003). For example, cross informant ratings (child-teacher and child-mother) of children's social competence and peer acceptance at Kindergarten and Year 1 ranged between 0.10 and 0.33 at Kindergarten, and 0.14 and 0.38 at Year 1 (Measelle et al., 1998). The stability and external validation of children's own self-reported social competence suggests that asking children to report on their own playfulness may be a promising avenue of research.

\section{5 | PLAYFULNESS AND SOCIAL BEHAVIOUR}

Children's play is a key context within which to assess development in general, a proposition which informs all playbased assessments, from the MacArthur Story Stem Battery, which broadly assess children's inner world along various themes including prosocial behaviour, empathy, and aggression (Bretherton \& Oppenheim, 2003) to the Autism Diagnostic Observation Schedule assessing the social and communicative impairments associated with Autism Spectrum Disorders (Lord et al., 2000). Importantly, the assumption underlying these assessments is that individual differences in children's play appear to reflect meaningful differences in social orientation, skills and wellbeing. 
Furthermore, within the developmental literature, intuitive links between children's play more broadly construed and adaptive social development (e.g., Ginsburg, 2007; Newton \& Jenvey, 2011), and the decline in play and child psychopathology (e.g., Gray, 2011) have been proposed.

However, the role of children's own perceptions of themselves as engaged and motivated to play for both positive and negative social behaviours has been overlooked. It is possible that those children who regard themselves as playful more readily take advantage of opportunities for social play and, in this way, playfulness may hone social skills, which in turns feeds back into children's own perceptions of themselves as engaged in play. Conversely, those children who experience behavioural problems, including both externalizing and internalizing problems, are likely to have problematic relationships with their peers, which may be reflected in their own perceptions of themselves as playful.

There is some empirical support for a link between playfulness and social behaviours in adults, with adult self-perceptions of playfulness shown to be associated with greater social intelligence (Proyer \& Ruch, 2011), happiness (Yue et al., 2016), and psychological wellbeing (Barnett, 2007; Proyer, 2013). The empirical support for this link in children is more limited and comes from research focusing on teacher-report playfulness. For example, Barnett (2018) found playfulness was significantly positively correlated with peer-reported social preference in children between 5 and 8 years of age. Surprisingly, while there was no association between teacher-rated playfulness and teacher-rated social competence for girls, for boys this association was significant and negative; this suggests that, at least from a teacher's perspective, playfulness is not inherently a sign of positive social competence (Barnett, 2018). In another study with a large sample of Korean children between 4 and 6 years of age, Choi and Kim (2006) found modest associations between subscales of the Test of Playfulness (Bundy et al., 2001) and features of children's social skills (e.g., cooperation).

With respect to the empirical support for an association between playfulness and problem behaviours, Barnett (2018) found a positive association between disruptive classroom behaviours (i.e., behaviours that interrupt classroom functioning) and playfulness but only for boys, and only for teacher-, not peer- or self-rated disruptive behaviours. While Barnett (2018) did not examine the association between playfulness and behavioural problems (e.g., externalizing and internalizing problems), these results suggest that the association between these two constructs may not be straight-forward and may depend on both the informant and gender of the child. Clearly more research is needed to explore the association between children's own perceptions of themselves as playful and social competence.

\section{SUMMARY AND OVERVIEW OF THE PRESENT PAPER}

Studying children's playfulness, rather than more context dependent measures of play skills or frequency of specific play behaviours, may avoid some of the pitfalls that have plagued the extant literature attempting to understand the role of play in children's social and emotional development. While teacher-reports of playfulness exist, it is likely that children are best placed to report on their own perceptions of themselves as playful.

Across two studies, we present the development and reliability of a self-reported measure of children's playfulness. Using best practice for the administration of measures assessing self-concept in young children (Eder, 1990; Measelle et al., 1998), Study 1 presents a cross-sectional examination of children's self-reported playfulness between 5 and 7 years of age, testing for differences in the items in the extent to which they are influenced by language ability, gender, and age, and ensuring test-retest reliability. Study 2 extends the findings of Study 1 by examining the factor structure and longitudinal measurement invariance of the self-reported playfulness scale and examines associations between playfulness, social competencies, and problem behaviours.

\subsection{Study 1}

A survey of the literature assessing children's playfulness revealed a set of possible items that could be adapted for use in a self-reported playfulness measure. Specifically, items were adapted from the self-reported Adult Playfulness 
Trait Scale (Shen et al., 2014), teacher-reported Children's Playfulness Scale (Barnett, 1990, 1991b) and the teacherreported Revised Knox Play Scale (Knox, 1997). A long-list of items was then sent to two experts in the field to determine if they felt the items were appropriate for assessing children's own self-assessments of playfulness, and if any additional items should be included. Ten items were selected from the long-list, with an additional item (I do silly things so other people will laugh) suggested for inclusion, resulting in a total of 11 items (see Table 1). The procedure for the administration of the Child Self-Reported Playfulness (CSRP) items was derived from the established literature assessing children's self-concept (Brown et al., 2008; Eder, 1990; Measelle et al., 1998) and involved a prerecorded video of puppets narrating pairs of contrasting statements. Children were asked to point to the puppet that was most like them.

In Study 1, the internal consistency of the final set of 11 CSRP items was investigated to assess if they were assessing a single construct, as well as the test-retest reliability in children between 5 and 7 years of age. While some studies have shown gender differences in children's playfulness (e.g., Barnett, 1991a; Hazar, Yildiz, Baydar, \& Karaçam, 2015), with boys more likely to score more highly on aspects of playfulness such as physical spontaneity, joy, and humor compared to girls (e.g., Zachopoulou, Trevlas, \& Tsikriki, 2004), when overall playfulness is examined typically no differences in boys and girls emerges (Barnett, 1990, 1991a, Barnett, 2018; Liebermann, 1977). It is important, therefore, to limit any item-level biases toward one specific gender. Finally, while existing research on children's self-concept suggests that children as young as 5 years of age have the cognitive skills required to report on their own self-concept (Davis-Kean \& Sandler, 2001), it is also important to ensure that children's responses to specific items do not vary as a function of age or language ability.

TAB LE 1 Study 1 and 2: Items and sources for the child self-reported playfulness scale (CSRP)

\begin{tabular}{|c|c|c|c|}
\hline & Left hand puppet & Right hand puppet & Source \\
\hline 1 & I do not really look for fun things to do & I often look for fun things to do & $\begin{array}{l}\text { Adult Playfulness Trait } \\
\text { Scale (Shen et al., 2014) }\end{array}$ \\
\hline 2 & I make up new games to play & I do not make up new games to play & $\begin{array}{l}\text { Children's Playfulness } \\
\text { Scale (Barnett, 1990) }\end{array}$ \\
\hline 3 & I do not sing and dance very much & I sing and dance a lot & $\begin{array}{l}\text { Knox Preschool Play Scale } \\
\text { (Knox, 1997) }\end{array}$ \\
\hline 4 & Other kids think I'm fun & Other kids do not really think I'm fun & $\begin{array}{l}\text { Adult Playfulness Trait } \\
\text { Scale (Shen et al., 2014) }\end{array}$ \\
\hline 5 & I do not tell funny stories & I tell funny stories & $\begin{array}{l}\text { Children's Playfulness } \\
\text { Scale (Barnett, 1990) }\end{array}$ \\
\hline 6 & $\begin{array}{l}\text { When someone else starts something } \\
\text { fun, sometimes I do not join in }\end{array}$ & $\begin{array}{l}\text { When someone else starts something } \\
\text { fun, I always join in }\end{array}$ & $\begin{array}{l}\text { Adult Playfulness Trait } \\
\text { Scale (Shen et al., 2014) }\end{array}$ \\
\hline 7 & $\begin{array}{l}\text { When I have to do something boring, } \\
\text { it's never fun }\end{array}$ & $\begin{array}{l}\text { When I have to do something boring, I } \\
\text { try to find a way to make it fun }\end{array}$ & $\begin{array}{l}\text { Adult Play Questionnaire } \\
\text { (Shen et al., 2014) }\end{array}$ \\
\hline 8 & I tell jokes & I do not tell jokes & $\begin{array}{l}\text { Children's Playfulness } \\
\text { Scale (Barnett, 1990) }\end{array}$ \\
\hline 9 & I always follow the rules & I do not always follow the rules & $\begin{array}{l}\text { Adult Playfulness Trait } \\
\text { Scale (Shen et al., 2014) }\end{array}$ \\
\hline 10 & I always play pretend & I do not really play pretend & $\begin{array}{l}\text { Children's Playfulness } \\
\text { Scale (Barnett, 1990) }\end{array}$ \\
\hline 11 & $\begin{array}{l}\text { I do not often do silly things so other } \\
\text { people will laugh }\end{array}$ & $\begin{array}{l}\text { I do silly things so other people will } \\
\text { laugh }\end{array}$ & \\
\hline
\end{tabular}

Note: Playful statements in italics. 


\section{7 | METHOD}

\section{1 | Participants}

Eighty-nine children ( $M_{\text {age }}=6.09$ years, $S D=0.71,45 \%$ girls) were recruited from either local schools or afterschool clubs in Cambridgeshire. The children participated in two sessions within six weeks of one another ( $M$ days between sessions $=14.22, S D=7.76$, range: $4-41$ days). Thirty-five children ( $39 \%, M_{\text {age }}=5.34$ years, $S D=0.45,49 \%$ girls) were in Reception or Year 1 and 54 children $\left(61 \%, M_{\text {age }}=6.58\right.$ years, $S D=0.30,43 \%$ girls) were in Year 2. Given the two different recruitment strategies for this study (local schools and afterschool clubs), we were not permitted to collect potentially identifiable information (i.e., ethnicity and parental education level) for those children seen in afterschool clubs. Of the 58 children recruited from schools, $47 \%$ were White British, $31 \%$ identified as White other (i.e., typically of broader European descent), $12 \%$ as Asian/Asian British, and 10\% as other or of mixed ethnicity. A total of $90 \%$ children had at least one parent who had completed tertiary education (i.e., completed at least an undergraduate degree). Given the afterschool clubs were serving the same local schools of the area, a similar demographic profile for the remaining children in this study is likely.

\section{2 | Procedure}

Children were seen by a research assistant individually in a quiet area of their school or afterschool club for both testing sessions. Other measures not relevant to current study were also administered during the sessions; order of tasks was counter-balanced across participants and sessions. The CSRP items were presented to each child via a tablet.

\section{8 | MEASURES}

\section{1 | Child self-reported playfulness (CSRP)}

Using the technique originally developed by Eder (1990) to assess young children's self-concept, the CSRP items were delivered as a pre-recorded "puppet show" video, a technique also employed by other researchers (e.g., de Rosnay \& Fink, 2012; Kochanska, Murray, \& Coy, 1997). The video featured two gender-neutral puppets, who introduced themselves and the rules of the task to the child. The puppets each described themselves using one of two bipolar statements, presented with a neutral intonation (see Table 1), and the child was asked to point to the puppet that was most like them. After two practice trials unrelated to study content, the children were presented with the 11 playfulness items. The experimenter sat next to the child during this task to record responses and to explain or prompt the child as necessary.

\section{2 | Verbal ability}

Given the range of ages of the children in the current study two different language measures were chosen. Both language assessments were conducted and scored according to the assessment manual by a trained researcher. The younger participants attending Reception or Year 1 completed the British Picture Vocabulary Scale (BPVS) to assess receptive language skills (Dunn \& Dunn, 2009). In this task, children saw four pictures on a page and were asked to choose the picture that best depicted the word spoken by the researcher. Each child started with the set relevant to their age, and the assessment was discontinued once the basal and ceiling sets were established. 
The older children in the sample completed the sentence comprehension (ACE-SC) subtest of assessment of comprehension and expression (Adams, Coke, Crutchley, Hesketh, \& Reeves, 2001) to assess receptive language skills. In this task, children saw a set of pictures and were asked to choose the picture that best represented the sentence spoken by the researcher. The ACE-SC has established internal consistency, Cronbach's $\alpha$ s between 0.64 and 0.75 and has been observed to adequately differentiate between children of different language abilities (Adams et al., 2001).

Research has demonstrated that the scores from the BPVS have a high concurrent correlation with scores derived from the ACE ( $r=0.66$, Adams et al., 2001). To allow for a comparison across the different language measures sample-centred BPVS scores for the younger children and a sample-centred score on the ACE-SC for older children were calculated, and then standardized again across the whole sample $(M=0, S D=0.99)$.

\section{3 | Analytic strategy}

Tetrachoric correlations were employed to examine the inter-item associations given the binary nature of the items, followed by an examination of internal consistency using Cronbach's alpha for both Session 1 and Session 2. Crosssession item correlations and Cohen's kappa were calculated to test temporal stability. Differential item functioning was tested across age and gender, and biserial correlations were run to test the effects of language ability on CSRP responses. Seven item responses (0.3\%) were missing across Session 1 and Session 2. Missing data were estimated using a non-parametric procedure based on a Random Forest trained on the observed values. The procedure was chosen as it is suitable for the categorical nature of the missing responses (Stekhoven \& Bühlmann, 2012).

\section{9 | RESULTS AND DISCUSSION}

The frequency of endorsement for each CSRP item across both sessions is presented in Table 2. Table 3 shows the within-session across item tetrachoric correlations for Session 1 and 2 . For the most part, items were positively associated. The scale had acceptable internal consistency at both time points, Session 1 Cronbach $\alpha=0.68$; Session 2 Cronbach $\alpha=0.78$. Overall mean of the CSRP scale at Session 1 was $8.62(S D=1.86)$ and at Session 2 was 8.13 $(S D=2.19)$.

\section{1 | Test-retest reliability}

To examine the proportion of agreement across the two testing sessions, we calculated Cohen's kappa ( $\kappa$ ) coefficient. The results presented in Table 2 suggest that all items showed fair to moderate agreement across the two sessions (Landis \& Koch, 1977), suggesting that the endorsement of specific items were relatively stable over the test-retest period. Furthermore, the majority of the item endorsements were significantly correlated across time (see Table 3 ).

\section{2 | Differential item functioning}

To ensure that children of different ages and gender had comparable odds of endorsing the CSRP items, we tested for differential item functioning (DIF). DIF was investigated across younger and older children by comparing the responses of older children to those of younger children from the first testing session. The unidimensionality of the measure was assumed and was later tested and confirmed in Study 2 (see below). We used the Mantel-Haenszel procedure, which is suitable for small sample sizes (Mantel \& Haenszel, 1959), and applied the Holm method to adjust for multiple comparisons (Kim \& Oshima, 2013). The results of the DIF analysis are presented in Table 2 and 


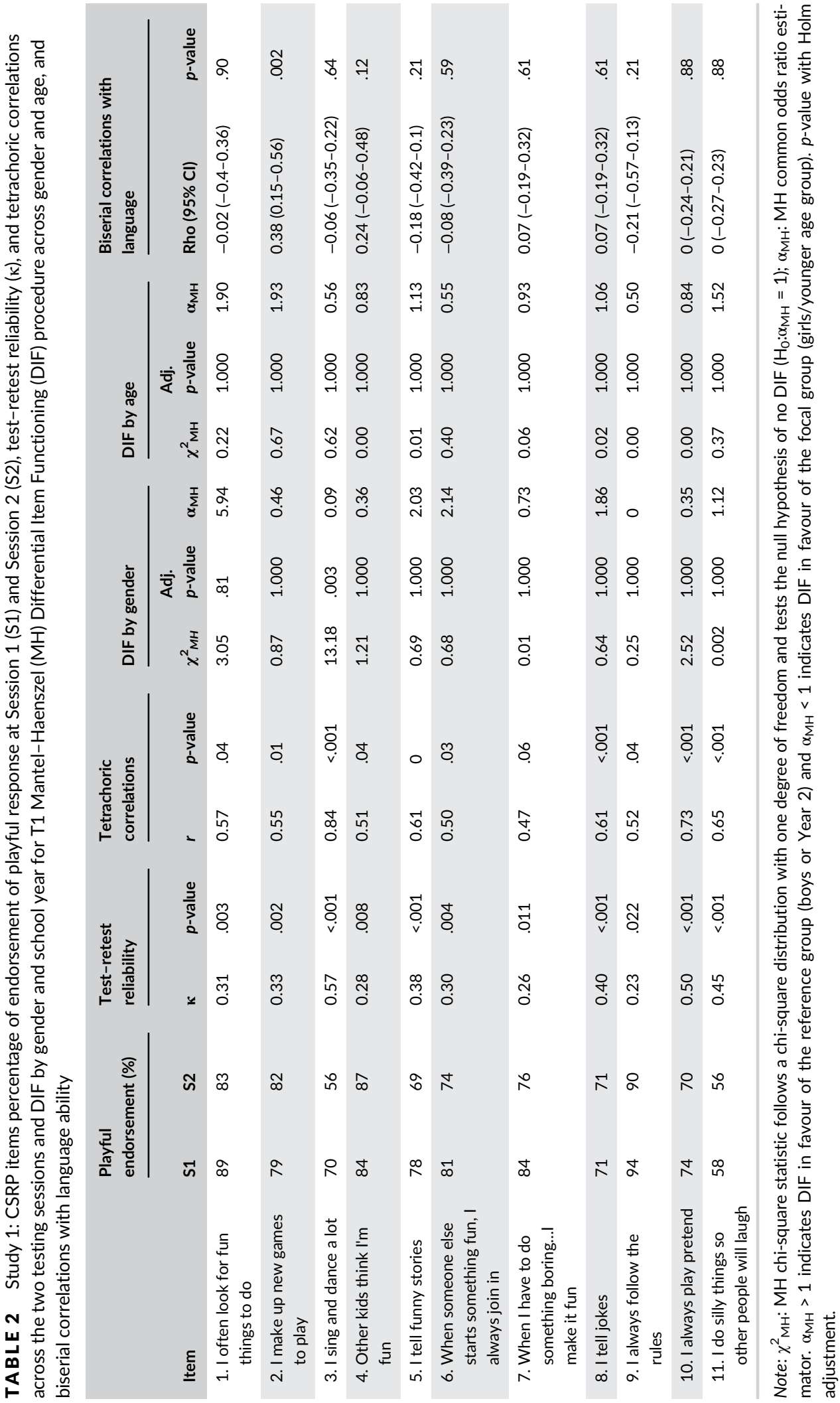




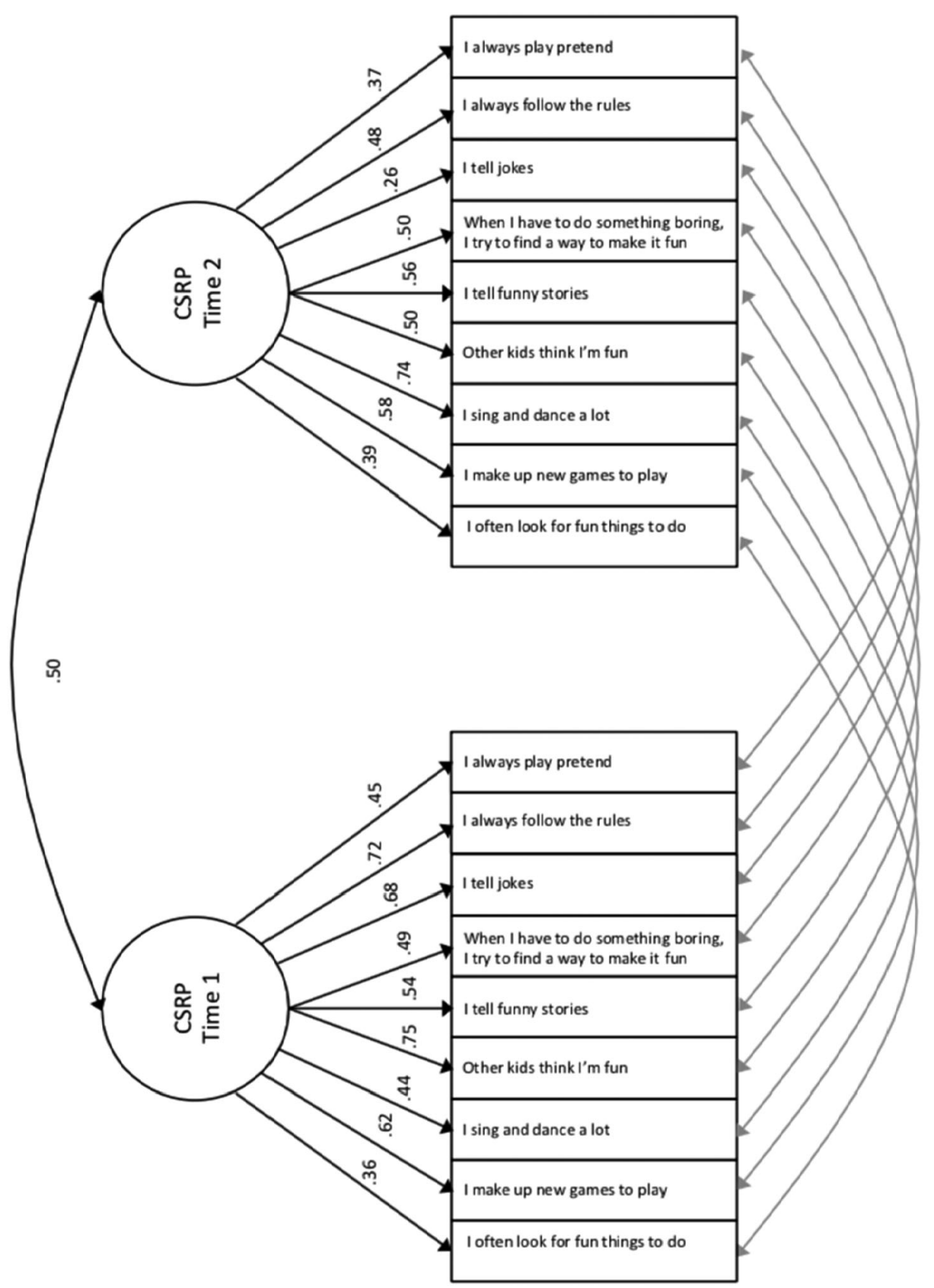


show that none of the items functioned differentially by age. However, with respect to gender, "I sing and dance a lot", was more likely to be endorsed by girls. Although, there were no overall mean differences in the CSRP scale as a function of gender at either Session 1 or Session 2, ps > .680.

To examine whether any of the items were related to language ability, biserial correlations were calculated across each item and receptive language ability. The results presented in Table 2 suggest that "I make up new games to play" was moderately and significantly related to receptive language ability.

The results of Study 1 suggest that there is test-retest stability in children' ability to report on their own perceptions of their playfulness between the two testing sessions. Endorsement across the 11 items was not influenced by the child's age, and appeared to be appropriate for both boys and girls, with the exception of the item, 'I sing and dance a lot', which was more likely to be endorsed by girls rather than boys. For the most part, frequency of endorsement across the different items was not associated with children's receptive language ability with the exception of 'I make up new games to play'.

\section{0 | STUDY 2}

Study 2 was designed to extend the findings of Study 1 by including a larger sample of similarly-aged children who were followed up one year later to test for the longitudinal stability of children's self-reported playfulness. The first aim of Study 2 was to further test the internal consistency of the CSRP by employing confirmatory factor analysis and longitudinal measurement invariance to test the degree to which items of the CSRP loaded onto a single latent factor and were indexing the same factor over time. The second aim of Study 2 was to examine the association of children's self-reported playfulness to their broader social behaviour using measures of teacher-rated play, social maturity and peer-reported social acceptance, and teacher-rated externalizing and internalizing problems.

Based on the findings of Study 1, we expected all items of the CSRP to load onto a single playfulness factor, and given the literature on the stability of playfulness as measured by teachers (e.g., Singer et al., 1980), we expected a degree of longitudinal stability over the one year between time-points. However, given that the ways in which playfulness is expressed by children likely changes as they develop, we also predicted that there might be some changes in which items might best reflect their perceptions of themselves as playful.

Based on the existing literature demonstrating associations between children's play and positive social behaviours, well-being, and problem behaviours (outlined in the Introduction), it was hypothesised that greater selfreported playfulness would be positively associated with teacher-reported play specifically, and with social competence more broadly using both teacher- and peer-reported measures. Finally, children's self-reported playfulness was predicted to be negatively associated with teacher-reported problem behaviours.

\section{1 | METHOD}

\section{1 | Participants and procedures}

Participants were 244 children in their first year of formal schooling (i.e., Reception, $46 \%$ girls) between the ages of 4.08 and 6.49 years $\left(M_{\text {age }}=5.09\right.$ years, $\left.S D=0.4\right)$. The sample was recruited (with written parental consent for each child) from 14 classrooms in eight schools in Cambridgeshire, UK. The majority of participants were of White British (55\%) or White other (i.e., broader European descent; 25\%), with the remaining sample classified as either Asian/ Asian British (12\%) or of other mixed ethnicity (7\%). A total of $84 \%$ of children had at least one parent who had completed tertiary education, while $9 \%$ of children were eligible for pupil premium (additional funding for disadvantaged children of all abilities). Five of the schools $\left(N=172, T 2: M_{\text {age }}=6.04, S D=0.37,43 \%\right.$ girls $)$ were enrolled in a longitudinal study and were followed up during the subsequent school year ( $M$ number of days between time-points $=294$, 


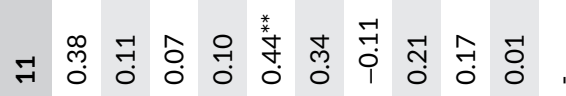

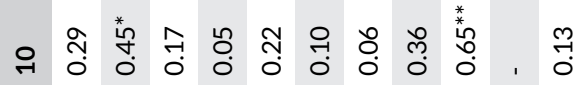

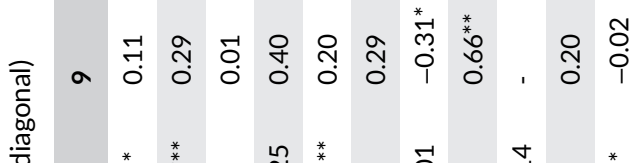

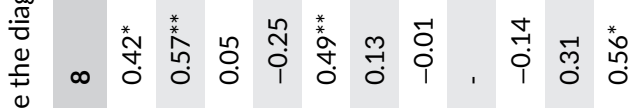

$\frac{\text { i }}{\stackrel{\circ}{\frac{0}{0}}}$

^

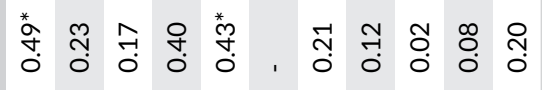

瞧

苾

苍

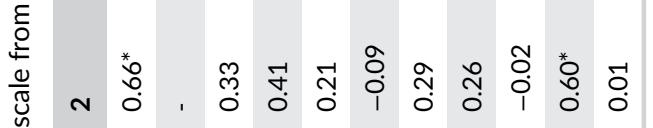

商

先

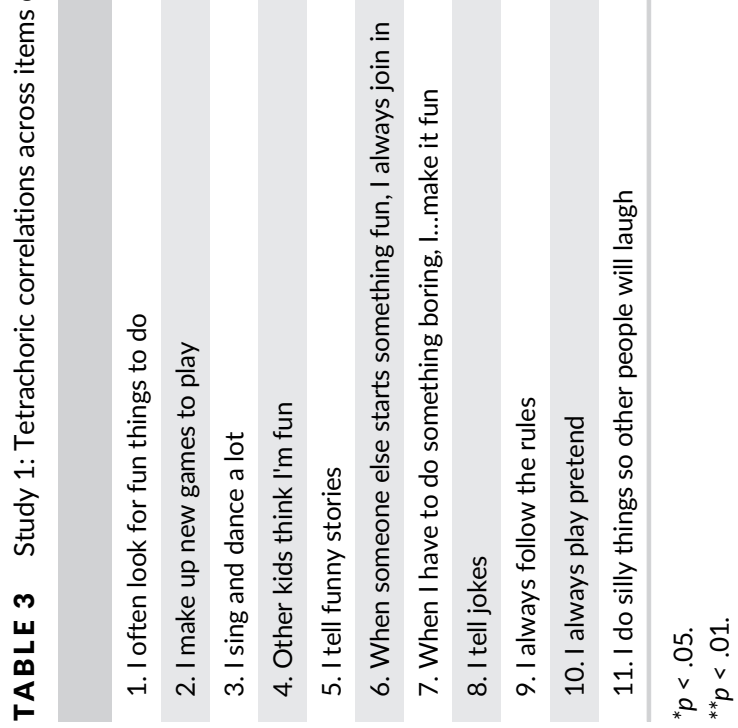


$S D=73.56$, range: $183-461$ days). At Time 2 ( $M_{\text {age }}=6.04$ years, $S D=0.4$, range: $5.34-7.50$ years), 11 children (6.4\%) of the 172 that were followed longitudinally had left their respective schools, their data along with any other missing data across all measures reported here (T1-1.86\% missing; T2-7.36\% missing) was estimated using a multiple imputation technique suitable for mixed data (Stekhoven \& Bühlmann, 2012). We did not estimate missing data for the children who were not enrolled in the longitudinal study.

There was no significant difference between children that were and were not included in the longitudinal follow-up with respect to parental education or pupil premium, $\chi^{2}<3.54, p>.060$. However because of the nature of the data collection procedure, that is, schools were visited in a fixed order through the school year and only whole schools were followed up, there was a significant difference in age and verbal ability between those schools that did and did not participate in the follow-up, as all follow-up schools were seen later in the school year, $t(240)$ $<10.46, p=.001$.

\section{2 | MEASURES}

\section{1 | Verbal ability}

The sentence structure and recalling sentences subtest of the CELF-Preschool 2-UK (Wiig, Secord, \& Semel, 2004) were administered at both time-points to capture receptive and expressive language abilities, respectively. The sentence structure subtest assesses a child's understanding of grammatical rules at the sentence level. For each of the 22 items, the experimenter read a sentence aloud and the child had to choose one of four presented pictures, which best corresponded to the sentence. For the recalling sentences subtest, which assess oral language expression, children were required to repeat sentences of increasing complexity read aloud by the experimenter. Scores on the two subsets were significantly associated at both time-points, T1: $r(242)=.67, p<.001$; T2: $r(170)=.57, p<.001$. The two scores were combined into a composite verbal ability score, which had good temporal stability over time, $r$ $(170)=.73, p<.001$.

\section{2 | Teacher-rated play interaction}

Teachers at both time-points completed the play interaction subscale from the Penn Interactive Peer Play Scale (PIPPS-I, Hampton \& Fantuzzo, 2003). This subscale comprised eight items describing positive peer play interactions (e.g., "encourages others to join play"), rated on a 4-point Likert scale ( 0 = Never, $1=$ Seldom, 2 = Often, 3 = Always). The play interaction subscale showed good internal consistency at both time points, T1: Cronbach $\alpha=0.89$, T2: Cronbach $\alpha=0.85$, and significant stability across time, $r(170)=0.46, p<.001$.

\section{3 | Teacher-rated social maturity}

Teachers completed the Peer Social Maturity Scale (PSMAT) at both time-points (Fink, de Rosnay, Peterson, \& Slaughter, 2013). The PSMAT assesses children social maturity relative to other children in the classroom, and consists of seven items describing behaviours that contribute to peer relationships (e.g., leadership, interactive social play, and social sensitivity). All items were rated on a 7-point Likert scale relative to the average child at this age (i.e., $1=$ very much less mature than the average child this age, to 7 = very much more mature than the average child this age). Excellent internal consistency was observed at both time-points, T1 Cronbach $\alpha=.87$, T2 Cronbach $\alpha=.87$, along with significant temporal stability, $r(170)=.62, p<.001$. 


\subsection{Peer-rated social preference}

Social preference was assessed using the widely used interview sociometric interview technique developed by Coie, Dodge, and Coppotelli (1982) to provide children's relative social standing in their classroom. Using photographs, children were asked to nominate three children in their class that "they like to play with the most" and three children "they do not like to play with". Cross-gender nominations were permitted (Terry \& Coie, 1991). To account for the differing numbers of children in each classroom, "like most" and "like least" scores were standardized. Children's standardized 'like least' total was subtracted from their standardized 'like most' total to calculate each child's peer preference in their classroom (Coie et al., 1982).

\section{5 | Teacher-rated problem behaviours}

To assess children's problem behaviours, teachers completed the externalizing and internalizing problem behaviour subscales of the Social Skills Rating System (SSRS, Gresham \& Elliott, 1990). Each subscale consisted of six items measuring the frequency of externalizing (e.g., 'fights with others) or internalizing (e.g., "appears lonely") problems in the classroom context, rated from 0 to 2 ( 0 = "never", 1 = "sometimes", 2 = "very often"). The SSRS has established internal consistency, $\alpha$ s ranging from 0.78 to 0.95 (Gresham \& Elliott, 1990). In the current sample, $\alpha$ s were between 0.90 and 0.97 across the two subscales at Time 1 and 2.

\section{6 | Analytic strategy}

Like Study 1, tetrachoric correlations were employed to examine the inter-item associations, followed by an examination of internal consistency using Cronbach's alpha for both Time 1 and Time 2. To test the relationship between the CSRP items and an underlying playfulness latent construct a confirmatory factor analysis was conducted whereby all 11 items of the CSRP scale were specified to load on a single factor (Brown, 2015). Longitudinal measurement invariance was then conducted by applying a single group CFA framework (Brown, 2015) to test for the equality of CSRP measurement across time and the temporal stability of children's perceptions of their own playfulness. Longitudinal measurement invariance was conducted in several steps, (a) equal form, (b) equal factor loadings, and (c) equal intercepts. Each of these steps is tested in turn (Brown, 2015). To test if a constrained model significantly reduces model fit a series of nested chi-square tests will be conducted. First, an equal form model was estimated to test the hypothesis that the latent variable structure is identical over time (Milsap \& Cham, 2012). In this model, the corresponding factor loadings were freely estimated and could take different values at each time-point. Error covariances for each item across time points were built into the model. Second, an equal factor loading model was defined, in which each item's factor loadings were constrained to equivalence across time. For each model, parameter estimates and model fit indices were inspected to evaluate model fit. Equality of indicator intercepts was then tested by constraining each pair of indicators over time to be equal. Equality of the indicators' error variances was not tested as this final equality restraint is highly stringent and has been found to rarely hold in realistic data (Brown, 2015).

The final set of analyses, based on the findings of Study 1, associations between CSRP factor scores at both Time 1 and 2 and children's gender and language ability were examined, followed by correlations between CSRP factor scores and children's social behaviour.

\section{3 | RESULTS AND DISCUSSION}

Descriptive statistics of all study variables are presented in Table 4, and inter-item correlations of the CSRP measure are presented in Table 5. At both time-points, the CSRP scale had good internal consistency, T1: Cronbach $\alpha=.79$; T2: Cronbach $\alpha=.80$. 


\subsection{Confirmatory factor analysis}

The internal consistency and significant correlations observed across most CSRP items suggest that they may be used as indicators to model a latent factor. To investigate this, we specified a confirmatory factory analysis (CFA) model using the Time 1 data $(N=244)$, where all 11 items were specified to load onto a single latent factor. Due of the ordinal nature of the CSRP scale, mean- and variance-adjusted weighted least squares (WLSMV) estimation was used. However, the fit indices suggested relatively poor model fit, $\chi^{2}(44)=78.84, p=.001$, root mean square error of approximation (RMSEA) $=.057$ [90\% Cl 0.036-0.077], comparative fit index (CFI) $=0.87$, Tucker-Lewis index $(T L I)=0.84$, and standardized root mean residual $(S R M R)=0.11$. Items 6 (When someone else starts something fun...) and 11 (I do silly things so other people will laugh) had relatively small factor loadings compared to the other items. Furthermore, the latent CSRP variable explained the smallest amount of variance in items 6 and $11\left(R^{2}\right.$ range of all 11 items: 0.14-0.44). Based on these fit indices and specific parameter estimates, items 6 and 11 were removed from the CFA and the model was re-run with the remaining nine CSRP items.

In comparison to the CFA model above, the nine-item fit indices suggested acceptable model fit, $\chi^{2}(27)=39.45$, $p=.06, \mathrm{RMSEA}=0.044$ [90\% Cl 0.00-0.071] $\mathrm{CFI}=0.94, \mathrm{TLI}=0.92$, and SRMR $=0.09$. All items significantly loaded onto the latent factor. Furthermore, the latent CSRP variable explained a significant amount of variance in all nine indicators ( $R^{2}$ range: 0.18-0.49). A longitudinal model was then constructed based on this nine-item model $(N=172)$, such that the nine CSRP items were specified to load onto a single latent factor at each time-point. The latent factors for playfulness at Time 1 and Time 2 were permitted to be correlated. The model was over-identified with $125 d f$ and $\chi^{2}=134.71, p=.261$. The overall goodness-of-fit indices suggested largely acceptable model fit: RMSEA $=.021$ [90\% Cl 0-.044], CFI $=.96$ and TLI $=.95$ and SRMR $=.12$. Completely standardized parameter estimates from this solution are presented in Figure 1. All parameters were statistically significant, and there was a significant association across the two playfulness factors over time. The amount of variance explained by the latent factors was significant for all items at Time 1 and at Time 2. These parameter estimates suggest that nine playfulness items at each time-point are reliable indicators of the underlying construct of playfulness.

\section{2 | Longitudinal invariance}

Having established an underlying construct of playfulness across both time-points, longitudinal measurement invariance was assessed to examine the measurement properties of playfulness over time. As noted above, there are several steps necessary to demonstrate measurement invariance: (a) equal form, (b) equal factor loadings, and (c) equal intercepts. Each of these steps will be tested in turn.

To test whether the factor structure was equivalent (equal form) at both time-points, the model was constrained to equal form by fixing the mean of the latent construct to zero at both time-points. Next, the model was assessed for the equality of factor loadings. The model fitted the data well with this additional constraint (see Table 6 ) and a nested $\chi^{2}$ test showed that constraining factor loadings to equality did not significantly reduce model fit. The model was then tested for the equality of indicator intercepts, again this model fitted the data well, and the $\chi^{2}$ difference test showed that the addition of these constraints did not significantly reduce model fit (see Table 6). As measurement invariance in the intercepts was supported, it suggests that observed levels of playfulness at a given level of the latent variable is equivalent across time. As form, factor loading and indicator intercepts were invariant across time, measurement invariance was supported. It can be concluded, therefore, that the measurement properties of playfulness are equivalent across 5 and 6 years of age.

\section{3 | Associations with gender and language ability}

As some items differed as a function of child gender and receptive language in Study 1, associations between playfulness, assessed as factor scores derived from the unconstrained CFA above, and gender and language ability were 
TABLE 4 Study 2: CSRP items frequency of endorsement, Means (M), SD, and CSRP temporal item stability (tetrachoric correlations) and stability of social behaviour (Pearson correlations) over Time 1 (T1) to Time 2 (T2)

\begin{tabular}{|c|c|c|c|}
\hline & $\begin{array}{l}\text { T1 playful } \\
\text { endorsement (\%) }\end{array}$ & $\begin{array}{l}\text { T2 playful } \\
\text { endorsement (\%) }\end{array}$ & $\mathrm{T} 1-\mathrm{T} 2 \mathrm{r}$ \\
\hline 1. I often look for fun things to do & 90 & 93 & $-0.13^{*}$ \\
\hline 2. I make up new games to play & 81 & 77 & 0.18 \\
\hline 3. I sing and dance a lot & 68 & 59 & $0.46^{*}$ \\
\hline 4. Other kids think I'm fun & 83 & 84 & 0.01 \\
\hline 5. I tell funny stories & 66 & 67 & $0.30^{*}$ \\
\hline 6. When someone else starts something fun, I always join in & 76 & 79 & $0.27^{*}$ \\
\hline 7. When I have to do something boring, I...make it fun & 77 & 77 & 0.14 \\
\hline 8. I tell jokes & 67 & 77 & 0.23 \\
\hline 9. I always follow the rules & 88 & 94 & $0.55^{* *}$ \\
\hline 10. I always play pretend & 70 & 66 & 0.17 \\
\hline \multirow[t]{2}{*}{ 11. I do silly things so other people will laugh } & 55 & 57 & $0.30^{*}$ \\
\hline & $\mathrm{T} 1 \mathrm{M}(\mathrm{SD})$ & $\mathrm{T} 2 \mathrm{M}(\mathrm{SD})$ & $\mathrm{T} 1-\mathrm{T} 2 \mathrm{r}$ \\
\hline Verbal ability & $37.30(11.82)$ & $43.18(8.83)$ & $0.73^{* * *}$ \\
\hline Peer social maturity & $28.78(7.42)$ & $29.90(7.50)$ & $0.62^{* * *}$ \\
\hline Play interaction & $14.84(3.05)$ & $15.24(3.51)$ & $0.46^{* * *}$ \\
\hline Internalizing problems & $2.86(2.56)$ & $1.87(2.42)$ & $0.41^{* * *}$ \\
\hline Externalizing problems & $2.12(2.86)$ & $1.37(2.42)$ & $0.72^{* * *}$ \\
\hline Social preference & $0(1.35)$ & $-0.01(1.52)$ & $0.33^{* * *}$ \\
\hline
\end{tabular}

explored. Given CSRP factor scores were non-normally distributed non-parametric statistics were employed. First, using the Mann-Whitney $U$ Test, differences in mean levels of playfulness between boys and girls were examined, and suggested no significant differences as a function of gender at T1: $W=6,416, p=.07$ (boys: $M=-0.13, S D=0.78$; girls: $M=0.06, S D=0.70$ ). At T2 however, girls rated themselves as significantly more playful than boys $W=2,625$, $p=.002$ (boys: $M=-0.18 ; S D=0.73$; girls: $M=0.15 ; S D=0.64$ ).

Associations between CSRP factor scores and a combined measure of children's expressive and receptive language ability was examined using non-parametric correlations and showed no significant concurrent association at either Time 1 or Time 2 between CSRP factor scores and language ability (see Table 7). However, there was a marginally significant negative longitudinal association between language ability at Time 1 and CSRP scores at Time 2, such that children with lower levels of language ability at age 5 rated themselves as more playful at age 6 .

\subsection{Associations with social behaviour}

To examine the association between children's self-reported playfulness and teacher- and peer-rated social behaviour non-parametric correlations across CSRP factor scores and other-informant ratings of social behaviour were conducted (see Table 7). Concurrently, the CSRP was marginally positively significantly associated to teacher ratings of play interaction at T1 and significantly positively related to teacher ratings of play at T2. However, there were no concurrent associations between the CSRP and teacher-rated social maturity, internalizing or externalizing problem 
न

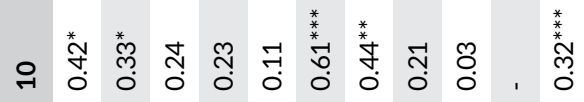

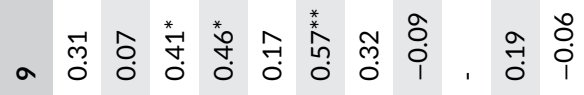

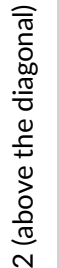

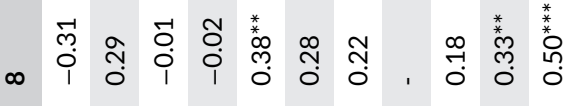

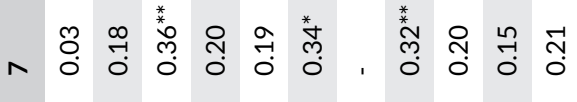

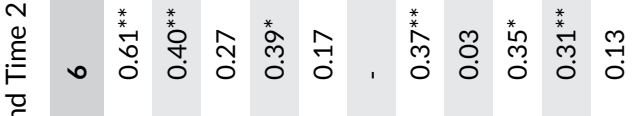

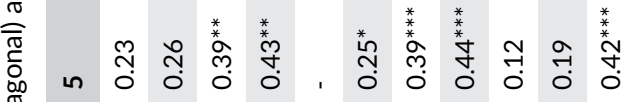

茛

並 m

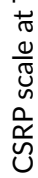

N

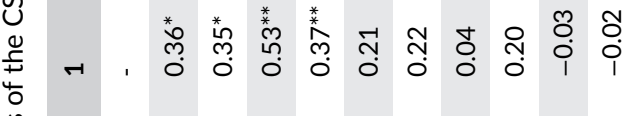

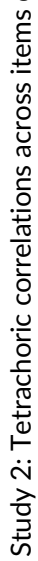

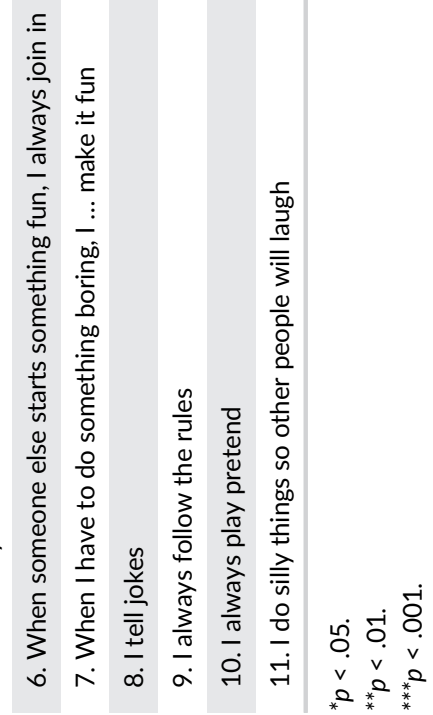


TABLE 6 Study 2: Longitudinal invariance of a measurement model of CSRP $(N=172)$

\begin{tabular}{lllllllll} 
& $\chi^{2}$ & $d f$ & CFI & $\chi^{2}$ diff & $\Delta d f$ & RMSEA (90\% CI) & TLI & SRMR \\
\hline Equal form & 134.71 & 125 & 0.96 & - & - & $0.021(0-0.044)$ & 0.95 & 0.12 \\
\hline Equal factor loadings & 147.65 & 134 & 0.94 & 12.94 & 9 & $0.024(0-0.045)$ & 0.93 & 0.14 \\
\hline Equal indicator intercepts & 143.10 & 131 & 0.95 & 4.55 & 3 & $0.023(0-0.045)$ & 0.94 & 0.13 \\
\hline
\end{tabular}

Abbreviations: $\mathrm{Cl}$, confidence interval; RMSEA, root mean square error of approximation; SRMR, standardized root mean residual; $\chi^{2}$ diff, nested $\chi^{2}$ difference.

\begin{tabular}{|c|c|c|}
\hline & CSRP T1 & CSRP T2 \\
\hline \multicolumn{3}{|l|}{ Time 1} \\
\hline Language ability & 0.05 & $-0.13^{+}$ \\
\hline Play interaction & $0.11^{+}$ & 0.07 \\
\hline Peer social maturity & 0.08 & 0.03 \\
\hline Peer-rated social preference & 0.04 & 0.05 \\
\hline Externalizing problems & -0.07 & -0.02 \\
\hline Internalizing problems & -0.01 & 0.01 \\
\hline \multicolumn{3}{|l|}{ Time 2} \\
\hline Language ability & 0.05 & -0.05 \\
\hline Play interaction & $0.17^{*}$ & $0.20^{*}$ \\
\hline Peer social maturity & 0.09 & 0.02 \\
\hline Peer-rated social preference & 0.08 & 0.08 \\
\hline Externalizing problems & $-0.22^{* *}$ & -0.12 \\
\hline Internalizing problems & -0.07 & -0.08 \\
\hline
\end{tabular}

TABLE 7 Study 2: Spearman correlations between Time $1(N=244)$ and Time $2(N=172)$ Child self-reported playfulness (CSRP) factor scores and children's language ability and teacherand peer-rated social behaviour

behaviours nor were there concurrent associations between the CSRP and peer-rated social preference at either time-point. Longitudinally, T1 CSRP was significantly positively associated with T2 teacher rating of play interaction, as well as significantly negatively associated with teacher-ratings of externalizing problems. No teacher- or peerrated social behaviour at T1 was associated with T2 CSRP.

Overall, bivariate associations and the results of the CFA and longitudinal invariance model suggest that the reduced nine CSRP items load onto a single factor and are stable over time. Furthermore, children's responses to the CSRP were only marginally associated with language ability at Time 2 , or gender at Time 1 . At Time 2 , when children were 6 years old, girls were significantly more likely to report themselves as playful compared to boys, a result not found in Study 1. Finally, while children's perceptions of their own playfulness were modestly associated with teacher-reported play interactions, it was not significantly concurrently associated with any other teacher- or peerreported social behaviour.

\section{4 | GENERAL DISCUSSION}

The current studies aimed to develop and test the psychometric properties of a self-reported playfulness measure for children and, together, suggest that that children as young as five years of age are able to provide insight 
into their playfulness. Unexpectedly, however, there were few associations between playfulness and children's teacher- or peer-reported social behaviour. The findings from the current studies have important implications for our understanding and measurement of children's play and playfulness and its role in broader social and cognitive development. We will return to discuss these implications after consideration of the psychometric findings.

\section{5 | PSYCHOMETRIC PROPERTIES OF THE CSRP}

Across both Study 1 and 2, the CSRP showed a relatively high degree of internal consistency implying that children responded in a coherent manner across all items. Importantly, the internal consistency within the CSRP found in both Study 1 and 2 is comparable to that of other studies investigating children's self-concept between ages 5 and 7 . For example, Brown et al. (2008) reported alphas between 0.68 (timidity) and 0.72 (agreeableness/negative affect), while Measelle et al. (1998), in their development of the BPI, reported alpha rates between 0.62 (social competence) and 0.78 (depression-anxiety). Both of these studies were across similar age groups and using a similar number of items per subscale as the current studies.

Furthermore, children's responses to the CSRP were not unduly influenced by age or language ability. In Study 1 , no item endorsement differed as a function of children's age, while only one item demonstrated positive associations with language ability. A close inspection of this item (I make up new games to play) shows it does not appear more linguistically challenging than the other items. In Study 2, using a combined measure of both receptive and expressive language was not concurrently associated with playfulness, while there was a marginal longitudinal association between children's language ability at age 5 and playfulness at age 6 . Clearly more research is needed to examine associations between playfulness and children demonstrating a broad range of linguistic ability. Nonetheless, the results of the current two studies are encouraging given the rapid linguistic gains experienced by children between 5 and 7 years of age and suggests that the wording of the items was largely appropriate for the early years of formal schooling.

Children's gender did appear to influence the degree to which they perceived themselves as playful. While Study 1 showed a single item differed as a function of gender, in Study 2, results showed that at 6 but not 5 years of age there was a mean difference in the degree to which boys and girls identified as playful, such that at 6 years of age girls perceived themselves as more playful than boys. This result clearly requires further investigation given that most studies do not show gender differences in teacherrated playfulness (e.g., Barnett, 1990; Liebermann, 1977), but may reflect a growing division between boys and girls with respect to the gender appropriateness of identifying as playful. This fits comfortably with research by Barnett (2018) that shows upon school entry boys and girls are equally likely to be rated as playful by their teachers, but that with age playful boys were more likely to be stigmatized by their teachers (Barnett, 2018), which may discourage boys from identifying as playful as they progress through school.

Finally, Study 1 and 2 together demonstrate that children's perceptions of their own playfulness are stable across time, both short-term (Study 1) and across a year (Study 2). Furthermore, the shortened nine-item CSRP demonstrated longitudinal measurement invariance providing initial evidence for the equality of measurement of playfulness between 5 and 6 years of age, that is, the nine items were a comparable index of children's playfulness at both age 5 and age 6 . Although the current findings are promising for the measurement of children's self-reported playfulness, further research is still needed to examine whether the scale is appropriate for use with older and younger children. Nonetheless, having a measure of children's playfulness that is appropriate across a broad age range sidesteps many of the challenges in creating structured contexts in which to observe children's play that are appropriate across development. 


\section{6 | CHILDREN'S PLAYFULNESS AND SOCIAL BEHAVIOUR}

While children's self-reported playfulness was modestly associated with teacher-reported play interactions both concurrently and longitudinally, it was unrelated to broader concurrent social behaviour as either rated by teachers or peers at both Time 1 and 2, a finding that is at odds with the assumption that children's play is associated with broader social development. There was, however, a modest negative association between earlier child perceptions of playfulness and later teacher-rated externalizing problems, cautiously suggesting that those children who perceived themselves as playful at 5 years of age were less likely to be rated as having externalizing problems by their teachers at 6 years of age. This result clearly needs further investigation but may be due to links between playful engagement and more adaptive self-regulation (Pellis \& Pellis, 2013). Overall, these results suggest that children's playfulness is not typically associated with social developmental outcomes, that is, those children that do not perceive themselves as playful are still considered socially skilled by their teachers and liked by their peers. Nor does it appear to be the case from the current findings that early playfulness provides children with opportunities for social interactions with peers that can be seen to hone or support the development of social skills.

\section{7 | IMPLICATIONS FOR THE MEASUREMENT OF CHILDREN'S PLAY}

The play literature has so far been dominated by teacher/parent-report and observations of children's play (both solitary and social peer play), while young children's own voice and perceptions of their play and playfulness tends to be overlooked. The psychometric properties of the CSRP suggest that it is possible to assess a novel dimension of children's play that has been hitherto challenging to capture using behavioural observations or teacher/parentreports and, by doing so, opens up a new opportunity for play research. Indeed, a first step would be exploring links between children's perceptions of their own playfulness and context-specific observations of children's peer play.

Although self-perceived playfulness was not associated with general measures of social development, the CSRP measure will enable play researchers to test hypothesised links between playfulness and creativity, and explore overlaps with other related constructs, such as humour. It may be particularly interesting to understand how playfulness is associated with humour, given a clear conceptual overlap between the two constructs and with social play interactions being a key setting for both children's playfulness and their expressions of humour (see Bergen, 2019); the extant literature on adult playfulness has demonstrated a positive association between playfulness and humour expressions (e.g., Yue et al., 2016). Importantly, the manner in which children use humour in their social interactions with peers has been shown to be associated with broader school adjustment (e.g., James \& Fox, 2018; Paine, Howe, Karajian, Hay, \& DeHart, 2019), and further research may uncover similar functions for a playful disposition. Furthermore, humour in early childhood has shown gender differences, with recent research showing that by 7 years of age, boys produce more humour compared to girls (Paine et al., 2019), suggesting that boys' and girls' humour, like the current findings for playfulness, may come to vary as a function of gender with development.

Understanding children's own perceptions of playfulness may also have important implications for our understanding of children experiencing difficulties in peer relationships. It may be that some children who struggle to initiate and maintain positive relationships with their peers have a mismatch between their own self-perceived playfulness in peer interactions and their peers' perceptions of their playfulness. This also opens up the possibility of asking children to report on their peers' playfulness, given the fact that peers can provide a unique perspective on their classmate's behaviour, and children are often asked to report on the behaviour, both positive and negative, of their peers (e.g., Coie \& Dodge, 1988; Younger, Schwartzman, \& Ledingham, 1985) 


\section{LIMITATIONS AND FUTURE RESEARCH}

Despite some key strengths of the current studies, namely a rigorous approach to the measurement of playfulness across both a large cross-sectional and longitudinal sample of children, a broad range of social outcomes derived from multiple-raters and the inclusion of comprehensive language measures, a number of limitations deserve mention. First, the validity of the newly developed CSRP is difficult to ascertain given the lack of "gold-standard" validated measures of children's play in the literature. One particularly illuminating area of future research will be an examination of the links between children's own perceptions of their playfulness and observations of play behaviours within a social interaction. It is possible, given the context-dependent nature of children's play (e.g., Etel \& Slaughter, 2019; Gibson et al., 2019) that associations between play behaviour and dispositional playfulness will differ depending on the play partner or play setting (e.g., independent compared to joint play; Etel \& Slaughter, 2019). Relatedly, the distinction between children's playfulness as a separate construct from social competence more broadly construed is still in question. Despite the findings of Study 2 suggesting that children's perceptions of their own playfulness was most closely associated with teacher-reports of play interactions rather than peer social maturity or peer-rated social preference, more research is needed to better understand both the concurrent and longitudinal association between children's playfulness (and play more generally) and their social competencies, especially in the domain of peer interactions.

Second, although we attempted to understand the association between children's self-perceptions of playfulness and other aspects of their social behaviour, we did not include a more general measure of child temperament or personality. It is likely that features of children's temperament, such as negative affect or agreeableness (Brown et al., 2008), may be strongly associated with the degree to which children perceive themselves as playful. In the adult playfulness literature, for example, the personality constructs of agreeableness and extraversion were both found to be significantly associated with playfulness (Proyer, 2012). Future studies including both self-reported playfulness and other aspects of children's self-concept are needed to clarify these relations and the specific role of playfulness for social behaviour with peers.

Finally, both groups of children in Study 1 and Study 2 were drawn from a relatively middle-class area of Cambridgeshire, UK, and as such do not necessarily represent the diversity of children in the country. Further research with the CSRP across a broad range of children is still needed to test its applicability.

\section{$19 \mid$ CONCLUSIONS}

The study of children's own perceptions of their playfulness shifts the focus from documenting and coding the observable behaviours of children in purported play contexts onto the psychological stance of the "player" and, in doing so, may avoid some of the pitfalls encountered when attempting to both uncover the quality or sophistication of children's play based on a single observed instance of play interactions, and the associations between children's play and their broader social and cognitive competencies. The CSRP presents an avenue by which to explore children's own self-reported playfulness that inherently incorporates children's own voice and perspective and captures the continuing nature of play across contexts and playmates, which we hope will allow researchers to study play in a more nuanced child-centric way that has been previously challenging.

\section{ACKNOWLEDGEMENTS}

Thank you to James Adams for preliminary literature reviewing. Thanks to participating children, schools and families. Jenny Gibson and Elian Fink are funded by the LEGO Foundation.

\section{CONFLICT OF INTEREST}

The authors declare no potential conflict of interest. 


\section{DATA AVAILABILITY STATEMENT}

The data that support the findings of this study are available from the corresponding author upon reasonable request.

\section{ORCID}

Elian Fink (1D) https://orcid.org/0000-0002-0328-9685

Silvana Mareva (iD) https://orcid.org/0000-0002-1728-9811

Jenny L. Gibson (1D) https://orcid.org/0000-0002-6172-6265

\section{REFERENCES}

Adams, C., Coke, R., Crutchley, A., Hesketh, A., \& Reeves, D. (2001). Assessment of comprehension and expression 6-11: nfer-Nelson.

Barnett, L. A. (1990). Playfulness: Definition, design, and measurement. Play and Culture, 3, 319-336.

Barnett, L. A. (1991a). Characterizing playfulness: Correlates with individual attributes and personality traits. Play and Culture, 4(4), 371-393.

Barnett, L. A. (1991b). The playful child: Measurement of a disposition to play. Play and Culture, 4(6), 51-74.

Barnett, L. A. (2007). The nature of playfulness in young adults. Personality and Individual Differences, 43(4), 949-958. https://doi.org/10.1016/j.paid.2007.02.018

Barnett, L. A. (2013). Children's perceptions of their play: Scale development and validation. Child Development Research, 2013, 1-18. https://doi.org/10.1155/2013/284741

Barnett, L. A. (2018). The education of playful boys: Class clowns in the classroom. Frontiers in Psychology, 9(232), 1-18. https://doi.org/10.3389/fpsyg.2018.00232

Boivin, M., Vitaro, F., \& Gagnon, C. (1992). A reassessment of the self-perception profile for children: Factor structure, reliability, and convergent validity of a French version among second through sixth grade children. International Journal of Behavioral Development, 15(2), 275-290. https://doi.org/10.1177/016502549201500207

Bretherton, I., \& Oppenheim, D. (2003). The MacArthur story stem battery: Development, administration, reliability, validity, and reflections about meaning. In R. N. Emde, D. Wolf, \& D. Oppenheim (Eds.), Revealing the inner worlds of young children: The MacArthur story stem battery and parent-child narratives (pp. 55-80). New York, NY: Oxford University Press.

Brown, G. L., Mangelsdorf, S. C., Agathen, J. M., \& Ho, M.-H. (2008). Young children's psychological selves: Convergence with maternal reports of child personality. Social Development, 17(1), 161-182. https://doi.org/10.1111/j.1467-9507. 2007.00421.x

Brown, T. A. (2015). Confirmatory factor analysis for applied research (2nd ed.). New York, NY: The Guildford Press.

Bundy, A. C., Nelson, L., Metzger, M., \& Bingaman, K. (2001). Validity and reliability of a test of playfulness. The Occupational Therapy Journal of Research, 21(4), 276-292. https://doi.org/10.1177/153944920102100405

Choi, M. S., \& Kim, J. H. (2006). The effect of playfulness on the social skills of young children: A study of gender differences. Korean Journal of Child Studies, 27(4), 103-116.

Coie, J. D., \& Dodge, K. A. (1988). Multiple sources of data on social behavior and social status in the school: A cross-age comparison. Child Development, 59(3), 815-829. https://doi.org/10.2307/1130578

Coie, J. D., Dodge, K. A., \& Coppotelli, H. (1982). Dimensions and types of social status: A cross-age perspective. Developmental Psychology, 18(4), 557-570. https://doi.org/10.1037/0012-1649.18.4.557

Davis-Kean, P. E., \& Sandler, H. M. (2001). A meta-analysis of measures of self-esteem for young children: A framework for future measures. Child Development, 72(3), 887-906. https://doi.org/10.1111/1467-8624.00322

de Rosnay, M., \& Fink, E. (2012). The development of moral motivation at 6 years of age. In R. Langdon \& C. Mackenzie (Eds.), Emotions, imagination, and moral reasoning (pp. 15-42). New York, NY: Psychology Press.

Donnellan, M. B., Trzesniewski, K. H., Robins, R. W., Moffitt, T. E., \& Caspi, A. (2005). Low self-esteem is related to aggression, antisocial behavior, and delinquency. Psychological Science, 16(4), 328-335. https://doi.org/10.1111/j.0956-7976. 2005.01535.x

Dunn, J., Cutting, A. L., \& Fisher, N. (2002). Old friends, new friends: Predictors of children's perspective on their friends at school. Child Development, 73(2), 621-635. https://doi.org/10.1111/1467-8624.00427

Dunn, L. M., \& Dunn, D. M. (2009). The British picture vocabulary scale. London, UK: GL Assessment Limited.

Eder, R. A. (1990). Uncovering young children's psychological selves: Individual and developmental differences. Child Development, 61(3), 849-863. https://doi.org/10.1111/j.1467-8624.1990.tb02827.x

Etel, E., \& Slaughter, V. (2019). Theory of mind and peer cooperation in two play contexts. Journal of Applied Developmental Psychology, 60, 87-95. https://doi.org/10.1016/j.appdev.2018.11.004 
Fantuzzo, J. W., \& Hampton, V. R. (2000). Penn interactive peer play scale: A parent and teacher rating system for young children. In K. Gitlin-Weiner, A. Sandgrund, \& C. Schaefer (Eds.), Play diagnosis and assessment (2nd ed., pp. 599-620). New York, NY: John Wiley \& Sons Inc.

Fink, E., de Rosnay, M., Peterson, C., \& Slaughter, V. (2013). Validation of the peer social maturity scale for assessing children's social skills. Infant and Child Development, 22(5), 539-552. https://doi.org/10.1002/icd.1809

Gibson, J., Fink, E., Torres, P., Browne, W. V., \& Mareva, S. (2019). Making sense of social pretense: The effect of the dyad, sex and language ability in a large observational study of children's behaviors in a social pretend play context. Social Development, 00,1-18. https://doi.org/10.1111/sode.12420

Ginsburg, K. R. (2007). The importance of play in promoting healthy child development and maintaining strong parent-child bonds. Pediatrics, 119(1), 182-191. https://doi.org/10.1542/peds.2006-2697

Glynn, M. A., \& Webster, J. (1992). The adult playfulness scale: An initial assessment. Psychological Reports, 71(1), 83-103. https://doi.org/10.2466/pr0.1992.71.1.83

Granleese, J., \& Joseph, S. (1994). Reliability of the Harter self-perception profile for children and predictors of global selfworth. The Journal of Genetic Psychology, 155(4), 487-492. https://doi.org/10.1080/00221325.1994.9914796

Gray, P. (2011). The decline of play and the rise of psychopathology in children and adolescents. American Journal of Play, 3 (4), 443-463.

Gresham, F. M., \& Elliott, S. N. (1990). Social skills rating system (SSRS). Circle Pines, MN: American Guidance Service.

Hampton, V. R., \& Fantuzzo, J. W. (2003). The validity of the Penn interactive peer play scale with urban, low-income kindergarten children. School Psychology Review, 32(1), 77-91. https://doi.org/10.1080/02796015.2003.12086184

Harkness, L., \& Bundy, A. C. (2001). The test of playfulness and children with physical disabilities. The Occupational Therapy Journal of Research, 21(2), 73-89. https://doi.org/10.1177/153944920102100203

Harter, S. (1985). Self-perception profile for children: Revision of the perceived competence scale for children. Denver, CO: University of Denver.

Hazar, M., Yildiz, M., Baydar, H. Ö., \& Karaçam, A. (2015). Assessment of playfulness among the children aged 10-14 years. The Anthropologist, 22(1), 50-58. https://doi.org/10.1080/09720073.2015.11891856

Howard, J. (2002). Eliciting young children's perceptions of play, work and learning using the activity apperception story procedure. Early Child Development and Care, 172(5), 489-502. https://doi.org/10.1080/03004430214548

Howard, J., \& McInnes, K. (2013). The impact of children's perception of an activity as play rather than not play on emotional well-being. Child: Care, Health and Development, 39(5), 737-742. https://doi.org/10.1111/j.1365-2214.2012. 01405.x

James, L. A., \& Fox, C. L. (2018). Longitudinal associations between younger children's humour styles and psychosocial adjustment. British Journal of Developmental Psychology, 36(4), 589-605. https://doi.org/10.1111/bjdp.12244

Kagen, S. L., Moore, E., \& Bredekamp, S. (1995). Considering children's early development and learning: Toward common views and vocabulary (report no. 95-03 ed.). Washington, DC: National Education Goals Panel.

Kim, J., \& Oshima, T. (2013). Effect of multiple testing adjustment in differential item functioning detection. Educational and Psychological Measurement, 73(3), 458-470. https://doi.org/10.1177/0013164412467033

Knox, S. (1997). Development and current use of the Knox preschool play scale. In L. D. Parham \& L. Fazio (Eds.), Play in occupational therapy for children (pp. 35-51). St Louis, MO: Mosby.

Kochanska, G., Murray, K., \& Coy, K. C. (1997). Inhibitory control as a contributor to conscience in childhood: From toddler to early school age. Child Development, 68(2), 263-277. https://doi.org/10.1111/j.1467-8624.1997.tb01939.x

Landis, J. R., \& Koch, G. G. (1977). The measurement of observer agreement for categorical data. Biometrics, 33, $159-174$. https://doi.org/10.2307/2529310

Leach, J., Howe, N., \& DeHart, G. (2019). A longitudinal investigation of siblings' and friends' features of connectedness and interaction quality during play. Early Education and Development, 30(6), 709-723. https://doi.org/10.1080/10409289. 2019.1597589

Lieberman, J. N. (1965). Playfulness and divergent thinking: An investigation of their relationship at the kindergarten level. The Journal of Genetic Psychology, 107(2), 219-224. https://doi.org/10.1080/00221325.1965.10533661

Liebermann, J. N. (1977). Playfulness: Its relationship to imagination and creativity. New York, NY: Academic Press.

Lillard, A. S., Lerner, M. D., Hopkins, E. J., Dore, R. A., Smith, E. D., \& Palmquist, C. M. (2013). The impact of pretend play on children's development: A review of the evidence. Psychological Bulletin, 139(1), 1-34. https://doi.org/10.1037/ a0029321

Lord, C., Risi, S., Lambrecht, L., Cook, E. H., Leventhal, B. L., DiLavore, P. C., ... Rutter, M. (2000). The autism diagnostic observation schedule-Generic: A standard measure of social and communication deficits associated with the Spectrum of autism. Journal of Autism and Developmental Disorders, 30(3), 205-223. https://doi.org/10.1023/A: 1005592401947

Mantel, N., \& Haenszel, W. (1959). Statistical aspects of the analysis of data from retrospective studies of disease. Journal of the National Cancer Institute, 22(4), 719-748. https://doi.org/10.1093/jnci/22.4.719 
Marsh, H. W., Ellis, L. A., \& Craven, R. G. (2002). How do preschool children feel about themselves? Unraveling measurement and multidimensional self-concept structure. Developmental Psychology, 38(3), 376-393. https://doi.org/10.1037/ 0012-1649.38.3.376

Measelle, J. R., Ablow, J. C., Cowan, P. A., \& Cowan, C. P. (1998). Assessing young children's views of their academic, social, and emotional lives: An evaluation of the self-perception scales of the Berkeley puppet interview. Child Development, 69 (6), 1556-1576. https://doi.org/10.1111/j.1467-8624.1998.tb06177.x

Milsap, R. E., \& Cham, H. (2012). Investigating factorial invariance in longitudinal data. In B. Laursen, T. D. Little, \& N. A. Card (Eds.), Handbook of developmental research methods (pp. 109-126). New York, NY: The Guildford Press.

Muris, P., Meesters, C., \& Fijen, P. (2003). The self-perception profile for children: Further evidence for its factor structure, reliability, and validity. Personality and Individual Differences, 35(8), 1791-1802. https://doi.org/10.1016/S0191-8869 (03)00004-7

Muys, V., Rodger, S., \& Bundy, A. C. (2006). Assessment of playfulness in children with autistic disorder: A comparison of the children's playfulness scale and the test of playfulness. OTJR: Occupation, Participation and Health, 26(4), $159-170$. https://doi.org/10.1177/153944920602600406

Newton, E., \& Jenvey, V. (2011). Play and theory of mind: Associations with social competence in young children. Early Child Development and Care, 181(6), 761-773. https://doi.org/10.1080/03004430.2010.486898

Paine, A. L., Howe, N., Karajian, G., Hay, D. F., \& DeHart, G. (2019). 'H, I, J, K, L, M, N, O, PEE! Get it? Pee!': Siblings' shared humour in childhood. British Journal of Developmental Psychology, 37, 336-353. https://doi.org/10.1111/ bjdp. 12277

Pellis, S., \& Pellis, V. (2013). The playful brain: Venturing to the limits of neuroscience. London, UK: Oneworld Publications.

Proyer, R. T. (2012). Examining playfulness in adults: Testing its correlates with personality, positive psychological functioning, goal aspirations, and multi-methodically assessed ingenuity. Psychological Test and Assessment Modeling, 54(2), 103. https://doi.org/10.5167/uzh-63532

Proyer, R. T. (2013). The well-being of playful adults: Adult playfulness, subjective well-being, physical well-being, and the pursuit of enjoyable activities. The European Journal of Humour Research, 1(1), 84-98. https://doi.org/10.7592/ EJHR2013.1.1.proyer

Proyer, R. T., \& Ruch, W. (2011). The virtuousness of adult playfulness: The relation of playfulness with strengths of character. Psychology of Well-Being: Theory, Research and Practice, 1(4), 1-12. https://doi.org/10.1186/2211-1522-1-4

Putnick, D. L., Hahn, C. S., Hendricks, C., \& Bornstein, M. H. (2019). Developmental stability of scholastic, social, athletic, and physical appearance self-concepts from preschool to early adulthood. Journal of Child Psychology and Psychiatry, 61, 95-103. https://doi.org/10.1111/jcpp.13107

Rothlein, L., \& Brett, A. (1987). Children's, teachers; and parents' perceptions of play. Early Childhood Research Quarterly, 2 (1), 45-53. https://doi.org/10.1016/0885-2006(87)90012-3

Shen, X. S., Chick, G., \& Zinn, H. (2014). Playfulness in adulthood as a personality trait: A reconceptualization and a new measurement. Journal of Leisure Research, 46(1), 58-83. https://doi.org/10.1080/00222216.2014.11950313

Singer, J. L., Singer, D. G., \& Sherrod, L. R. (1980). A factory analytic study of preschoolers' play behavior. Academic Psychology Bulletin., 2(2), 143-156.

Stekhoven, D. J., \& Bühlmann, P. (2012). MissForest-Non-parametric missing value imputation for mixed-type data. Bioinformatics, 28(1), 112-118. https://doi.org/10.1093/bioinformatics/btr597

Terry, R., \& Coie, J. D. (1991). A comparison of methods for defining sociometric status among children. Developmental Psychology, 27(5), 867-880.

Trevlas, E., Grammatikopoulos, V., Tsigilis, N., \& Zachopoulou, E. (2003). Evaluating playfulness: Construct validity of the children's playfulness scale. Early Childhood Education Journal, 31(1), 33-39. https://doi.org/10.1023/A: 1025132701759

UNICEF (2018). Learning through play: Strengthening learning through play in early childhood education programmes. Retrieved from https://www.unicef.org/sites/default/files/2018-12/UNICEF-Lego-Foundation-Learning-throughPlay.pdf

Wiig, E. H., Secord, W., \& Semel, E. M. (2004). CELF preschool 2: clinical evaluation of language fundamentals preschool: Pearson/PsychCorp.

Wing, L. A. (1995). Play is not the work of the child: Young children's perceptions of work and play. Early Childhood Research Quarterly, 10(2), 223-247. https://doi.org/10.1016/0885-2006(95)90005-5

Youngblade, L. M., \& Dunn, J. (1995). Individual differences in young children's pretend play with mother and sibling: Links to relationships and understanding of other people's feelings and beliefs. Child Development, 66(5), 1472-1492. https:// doi.org/10.2307/1131658 
Younger, A. J., Schwartzman, A. E., \& Ledingham, J. E. (1985). Age-related changes in children's perceptions of aggression and withdrawal in their peers. Developmental Psychology, 21(1), 70-75. https://doi.org/10.1037/00121649.21.1.70

Yue, X. D., Leung, C.-L., \& Hiranandani, N. A. (2016). Adult playfulness, humor styles, and subjective happiness. Psychological Reports, 119(3), 630-640. https://doi.org/10.1177/0033294116662842

Zachopoulou, E., Trevlas, E., \& Tsikriki, G. (2004). Perceptions of gender differences in playful behaviour among kindergarten children. European Early Childhood Education Research Journal, 12(1), 43-53. https://doi.org/10.1080/ 13502930485209301

How to cite this article: Fink E, Mareva S, Gibson JL. Dispositional playfulness in young children: A crosssectional and longitudinal examination of the psychometric properties of a new child self-reported playfulness scale and associations with social behaviour. Inf Child Dev. 2020;29:e2181. https://doi.org/10. 1002/icd.2181 